\title{
Indirect assessment of the fusion properties of choline chloride from solid-liquid equilibria data
}

\author{
Luis Fernandez ${ }^{\text {a, }}$, , Liliana P. Silva ${ }^{b}$, Mónia A.R. Martins ${ }^{b}$, Olga Ferreira ${ }^{c}$, Juan Ortega ${ }^{\text {, }}$, \\ Simão P. Pinho ${ }^{c}$, João A.P. Coutinho ${ }^{\text {b, * }}$ \\ a Laboratorio de Termodinamica y Fisicoquímica de Fluidos, 35071-Parque Científico-Tecnológico, Universidad de Las Palmas de Gran Canaria, Canary \\ Islands, Spain \\ ${ }^{\mathrm{b}}$ CICECO-Instituto de Materiais de Aveiro, Departamento de Química, Universidade de Aveiro, 3810-193 Aveiro, Portugal

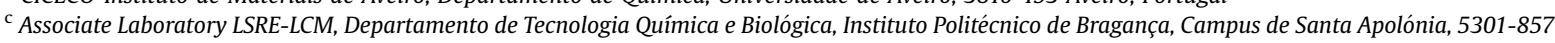 \\ Bragança, Portugal
}

\section{A R T I C L E I N F O}

\section{Article history:}

Received 8 February 2017

Received in revised form

16 March 2017

Accepted 17 March 2017

Available online 21 March 2017

\section{Keywords:}

Choline chloride

Deep eutectic solvents

Melting properties

Experimental

Ideal solutions

\begin{abstract}
A B S T R A C T
The temperature and enthalpy of fusion of choline chloride - $[\mathrm{Ch}] \mathrm{Cl}$ - are not directly measurable since this compound decomposes upon melting. Yet, given the wide use of this compound in the preparation of deep eutectic solvents (DES), its thermophysical fusion properties are very important for a better understanding of these mixtures and the thermodynamic description of their solid-liquid phase diagrams. In this work, the fusion properties of choline chloride were estimated using the solubility curves of choline chloride in ten different ionic compounds, forming simple binary eutectic mixtures with quasiideal liquid phases. Experimental solid-liquid equilibria data for these systems $-[\mathrm{Ch}] \mathrm{Cl}+$ ionic compounds- were measured, and the ideality of the systems assessed through the quantification of the activity coefficients and their comparison in each pair of binary solutions. The values estimated for the fusion properties of choline chloride are $T_{\text {fus, }[\mathrm{Ch}] \mathrm{Cl}}=597 \pm 7 \mathrm{~K}_{\text {and }} \Delta_{\text {fus }} H_{[\mathrm{Ch}] \mathrm{Cl}}=4300 \pm 600 \mathrm{~J} \mathrm{~mol}^{-1}$. These were additionally checked by thermodynamic consistency tests and by the prediction of the solid-liquid curves with COSMO-RS model. The results obtained with both procedures allow us to guarantee the usefulness and robustness of the estimated data.
\end{abstract}

() 2017 Elsevier B.V. All rights reserved.

\section{Introduction}

Deep eutectic solvents (DES) are a neoteric, ecofriendly, class of solvents intensively investigated in the past few years [1]. Prepared by mixing Lewis and Brønsted acids and bases, their combination gives rise to low melting points mixtures by hydrogen bond complexation [2]. The formulation does not involve any chemical reaction or additional purification steps. Additionally, the fact that their structures can be adjusted by selecting the hydrogen-bond donor-acceptor combinations, and that their phase behavior and physical-chemical properties can be tailored, classifies them as designer solvents [3]. Their exceptional properties [2,4] make them interesting in many fields [2,5-7]. Owing to their promising applications, efforts have been devoted to their characterization [2].

Due to its good solvent capacity, non-toxicity, biodegradability

\footnotetext{
* Corresponding author.

E-mail address: jcoutinho@ua.pt (J.A.P. Coutinho).
}

and economical synthesis, choline chloride $([\mathrm{Ch}] \mathrm{Cl})$ is by far the most common compound used in DES formulation [2,7,8]. Usually, $[\mathrm{Ch}] \mathrm{Cl}$ is combined with safe hydrogen bond donors such as polyols, urea, carboxylic acids or sugars [1,9,10], and their main applications include organic synthesis, biocatalysis and electrochemistry $[2,7,11]$. The knowledge of the fusion properties of $[\mathrm{Ch}] \mathrm{Cl}$ is thus of utmost importance for a thermodynamic characterization of the choline-based DES, including the eutectic points and the complete description of the solid-liquid phase diagrams. This is relevant for the design and optimization of processes involving DES, including the search and selection of the best mixture for a particular application. As choline chloride decomposes before/upon melting [12] the use of direct technics for the measurement of its fusion properties cannot be applied. So far, a value of $575.15 \mathrm{~K}$ [1] is usually used as the melting temperature, however that is probably a decomposition temperature. No melting enthalpy was assigned to this compound until now.

In this work an indirect method to estimate the fusion temperature and enthalpy of $[\mathrm{Ch}] \mathrm{Cl}$ is applied. This is based on the 
evaluation of the solid-liquid phase equilibria of a set of quasi-ideal binary solutions formed by $[\mathrm{Ch}] \mathrm{Cl}$ and other ionic compounds. Previous works [13-15] have shown that mixtures of ionic liquids, even with melting points above $373.15 \mathrm{~K}$, often form quasi-ideal mixtures. Thus, the solubility curves of ten eutectic systems formed by $[\mathrm{Ch}] \mathrm{Cl}$ and the ionic compounds (IC): choline acetate ([Ch][Ac]), choline propanoate ([Ch][Prop]), choline butanoate ([Ch][Buta]), tetrabutylammonium chloride $\left(\left[\mathrm{N}_{4444}\right] \mathrm{Cl}\right)$, tetrabutylphosphonium chloride $\left(\left[\mathrm{P}_{4444}\right] \mathrm{Cl}\right)$, benzyldimethyl(2-hydroxyethyl)-ammonium chloride ([BzCh]Cl), 1-butyl-1-methylpyrrolidinium chloride $\left(\left[\mathrm{C}_{4} \mathrm{mpyr}\right] \mathrm{Cl}\right)$, choline bis(trifluoromethylsulfonyl) imide ([Ch] $\left.\left[\mathrm{NTf}_{2}\right]\right)$, 1-ethyl-3-methylimidazolium chloride $\left(\left[\mathrm{C}_{2} \mathrm{mim}\right] \mathrm{Cl}\right)$ and 1-(2-hydroxyethyl)-3-methylimidazolium chloride, $\left(\left[\mathrm{C}_{2} \mathrm{OHmim}\right] \mathrm{Cl}\right)$, are measured. The quasi-ideality of each mixture is firstly assessed calculating the activity coefficients by COSMO-RS [16], and using the experimental data to compare the similarity of $[\mathrm{Ch}] \mathrm{Cl}$ activity coefficients in each pair of binary systems. The solubility data is then used to estimate the fusion properties of $[\mathrm{Ch}] \mathrm{Cl}$ by linear regression of the solid-liquid equilibrium equation. The final results are checked using two independent procedures: 1) evaluation of the thermodynamic consistency of the experimental data, and 2) estimation of the solid-liquid phase diagrams by COSMO-RS and comparison with the experimental phase equilibria diagrams.

\section{Experimental}

\subsection{Materials}

The source, purity and temperature of fusion of the compounds used in this work are described in Table 1 while the structures, CAS and full chemical names are presented in Fig. 1. [Ch][Prop] and [Ch] [Buta] were synthetized in our laboratory following standard procedures presented in Supplementary Information. Before use, all individual compounds were purified under vacuum $(0.1 \mathrm{~Pa}$ and $298 \mathrm{~K}$ ), for at least $72 \mathrm{~h}$. The water content was then measured by Karl-Fisher and was found to be always lower than 600 ppm.

\subsection{Methods}

The melting temperatures were determined with an automatic glass capillary device model M-565 from Buchi (100-240 V, $50-60 \mathrm{~Hz}, 150 \mathrm{~W}$ ), which has a temperature resolution of $0.1 \mathrm{~K}$.
Since many ionic compounds are highly hygroscopic, in particular choline chloride, mixtures were prepared inside a dry-argon glovebox, at room temperature using an analytical balance model ALS $220-4 \mathrm{~N}$ from Kern with an accuracy of $\pm 0.002 \mathrm{~g}$. Vials with mixtures were, whenever possible, heated under stirring until complete melting and then recrystallized. The solid mixtures were ground in the glove-box and the powder filled into a capillary. A heating rate of $0.5 \mathrm{~K} \mathrm{~min}^{-1}$ was used in all cases, and the melting procedure repeated at least two times. The estimated uncertainty of the melting temperatures is better than $1.2 \mathrm{~K}$. The thermogravimetric analysis of pure choline chloride can be found in Fig. S1.

In a few specific cases indicated in Table 1, differential scanning calorimetry (DSC) was used. The melting properties were determined using a Hitachi DSC7000X model working at atmospheric pressure. Samples of approximately $5 \mathrm{mg}$ tightly sealed in aluminium pans were submitted at least to 3 repeated cooling-heating cycles at $2 \mathrm{~K} \mathrm{~min}^{-1}$. The thermal transitions temperatures were taken as the peak temperature. The temperature uncertainty calculated through the average of the standard deviation of several consecutive measurements was better than $\pm 0.1 \mathrm{~K}$. The equipment was previously calibrated with several standards with weight fraction purities higher than $99 \%$.

\section{Models and data processing}

For eutectic systems with complete immiscibility in the solid phase the phase equilibrium can be described by Ref. [26]:

$\ln \left(x_{i} \gamma_{i}^{L}\right)=\frac{\Delta_{f u s} H}{R}\left(\frac{1}{T_{f u s}}-\frac{1}{T}\right)+\frac{\Delta_{f u s} C_{p}}{R}\left(\frac{T_{f u s}}{T}-\ln \frac{T_{f u s}}{T}-1\right)$

where $x_{i}$ is the mole fraction solubility of compound $i$ and $\gamma_{i}^{L}$ its activity coefficient in the liquid phase, $\Delta_{f u s} H$ and $T_{\text {fus }}$ are the enthalpy and temperature of fusion, respectively, $R$ is the ideal gas constant, $T$ is the absolute temperature, and $\Delta_{f u s} C_{p}$ is the difference between the heat capacity of the compound $i$ in liquid and solid phases. Since values for the heat capacities of most compounds here studied have not yet been measured, and for $[\mathrm{Ch}] \mathrm{Cl}$ it is not measurable since the compound decomposes before melting, the last term in Eq. (1) is neglected in this work. Moreover, even when that data are available, the contribution of this term to the phase equilibrium calculations has been shown to be very small $[27,28]$. If the liquid phase is an ideal mixture, Eq. (1) becomes,

Table 1

Pure component properties.

\begin{tabular}{|c|c|c|c|c|c|}
\hline \multirow[t]{2}{*}{ Compound } & \multirow[t]{2}{*}{ Source } & \multirow[t]{2}{*}{ Mass purity/\% } & \multicolumn{2}{|l|}{$T_{\text {fus }} / \mathrm{K}$} & \multirow[t]{2}{*}{$\Delta_{\text {fus }} H / \mathrm{J} \cdot \mathrm{mol}^{-1}$} \\
\hline & & & Exp. & Lit. & \\
\hline$[\mathrm{Ch}] \mathrm{Cl}$ & Acros Organics & 98 & - & $575.15[1]$ & - \\
\hline$[\mathrm{Ch}][\mathrm{Ac}]$ & Iolitec & $>99$ & $362.62^{\mathrm{a}}$ & $324.15[17] / 345.15[18]$ & $8881.7^{\mathrm{d}}$ \\
\hline$[\mathrm{Ch}][\text { Prop }]^{\mathrm{c}}$ & - & $99^{\mathrm{e}}$ & $282.57^{b}$ & - & $2238.6^{\mathrm{b}}$ \\
\hline$[\mathrm{Ch}][\text { Buta }]^{\mathrm{C}}$ & - & $99^{\mathrm{e}}$ & $315.98^{b}$ & 318.15 [19] & $8793.6^{\mathrm{b}}$ \\
\hline$\left[\mathrm{N}_{4444}\right] \mathrm{Cl}$ & Sigma-Aldrich & 97 & $342.82^{\mathrm{a}}$ & $348.15[20]$ & $19430^{\mathrm{d}}$ \\
\hline$\left[\mathrm{P}_{4444}\right] \mathrm{Cl}$ & Cytec & 97 & $339.46^{\mathrm{a}}$ & $338.15[21]$ & - \\
\hline$[\mathrm{BzCh}] \mathrm{Cl}$ & Aldrich & 97 & $351.42^{\mathrm{a}}$ & - & $8730^{\mathrm{d}}$ \\
\hline$\left[\mathrm{C}_{4} \mathrm{mpyr}\right] \mathrm{Cl}$ & Iolitec & 99 & $472.98^{\mathrm{a}}$ & $>387.15[22]$ & $30896^{\mathrm{d}}$ \\
\hline$[\mathrm{Ch}]\left[\mathrm{NTf}_{2}\right]$ & Iolitec & 99 & $305.65^{b}$ & $303.15[23]$ & $1226.5^{\mathrm{b}}$ \\
\hline$\left[\mathrm{C}_{2} \mathrm{mim}\right] \mathrm{Cl}$ & Iolitec & 98 & $350.42^{\mathrm{a}}$ & $363.15[24]$ & $8588^{\mathrm{d}}$ \\
\hline$\left[\mathrm{C}_{2} \mathrm{OHmim}\right] \mathrm{Cl}$ & Iolitec & 99 & $358.88^{\mathrm{a}}$ & 335.15 [25] & $20974^{\mathrm{d}}$ \\
\hline
\end{tabular}




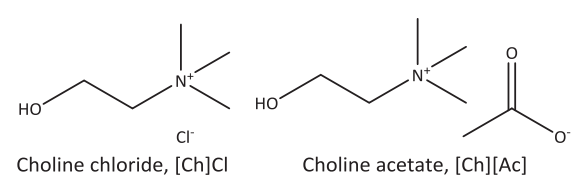
67-48-1

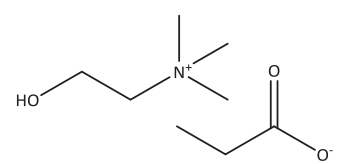

Choline propanoate, [Ch][Prop] 106572-68-3

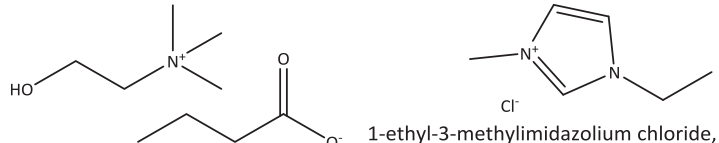

1-ethyl-3-methylimidazolium chloride, $\left[\mathrm{C}_{2} \mathrm{mim}\right] \mathrm{Cl}$

Choline butanoate, [Ch][Buta] 65039-09-0

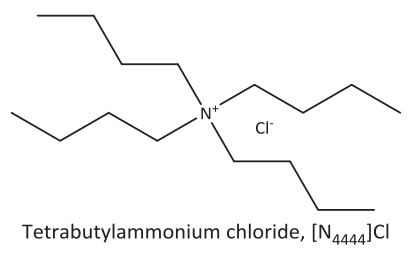
1112-67-0

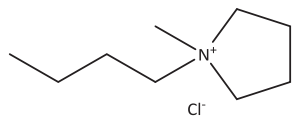

1-butyl-1-methylpyrrolidinium chloride, $\left[\mathrm{C}_{4} \mathrm{mpyr}\right] \mathrm{Cl}$ 479500-35-1

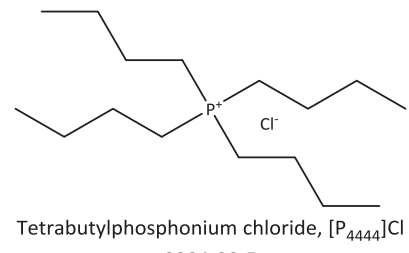
2304-30-5

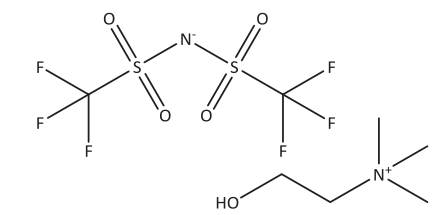

Choline bis((trifluoromethyl)sulfonyl)imide, [Ch] $\left[\mathrm{NTf}_{2}\right]$ 827027-25-8

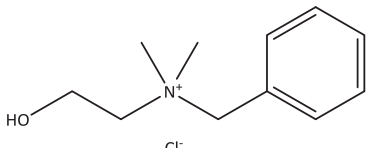

Benzyldimethyl(2-hydroxyethyl)ammonium chloride, [BzCh]Cl 7221-40-1

Fig. 1. Chemical names, CAS and structures of the ionic compounds investigated.

$\ln \left(x_{i}\right)=\frac{\Delta_{f u s} H}{R}\left(\frac{1}{T_{f u s}}-\frac{1}{T}\right)$

Eq. (2) shows a linear relationship between $\ln \left(x_{i}\right)$ and $1 / T$ and thus, a linear regression of a set of experimental data for the solubility of choline chloride, in ideal systems, can provide an indirect estimation of the $[\mathrm{Ch}] \mathrm{Cl}$ fusion properties. In the same way, Eq. (2) provides an estimation of the enthalpies of fusion for the other components for which these data are not available. These estimated enthalpies of fusion are shown in Table 1.

\subsection{Assessment of the systems ideality}

The use of Eq. (2) implies that the experimental data used in the regression must come from systems with an ideal, or quasi-ideal, liquid phase. In this work, from a set of 21 binary systems containing $[\mathrm{Ch}] \mathrm{Cl}$, a group of 10 was selected after checking the ideality of the liquid phase of those systems using, initially, COSMO-RS.

COSMO-RS allows the prediction of the activity coefficients of each compound in a mixture without any empirical data. The activity coefficients at 300,400 and $500 \mathrm{~K}$ of the $[\mathrm{Ch}] \mathrm{Cl}(1)+\mathrm{IC}(2)$ systems were estimated by COSMO-RS and this information used to assess the ideality of the solutions. Before the estimations, all the IC structures were optimized [29]. The ions of each compound were optimized simultaneously as an ion pair. On a second step, the COSMO file of each structure was generated by Gaussian, computing the ideal screening charges on the molecular surface at the BVP86/TZVP/DGA level [29].

Despite its usefulness, COSMO-RS is a predictive tool and thus, additional experimental-based verifications must be performed. For this reason, an empirical procedure named $r$-method was further employed to check the similarity of the behavior of each pair of binary solutions. This approach is based on the constancy of the second term of the equilibrium in Eq. (1), when the solid phase is the same, in this study $[\mathrm{Ch}] \mathrm{Cl}$, and so the product $x_{i} \gamma_{i}^{L}$ is independent of the second compound in solution. This allows us to establish the equality between the activities of $[\mathrm{Ch}] \mathrm{Cl}$ in two different binary solutions at the same temperature:

$x_{[C h] C l, A} \gamma_{[C h] C l, A}=x_{[C h] C l, B} \gamma_{[C h] C l, B}$

where $\mathrm{A}$ and $\mathrm{B}$ are two different ionic compounds forming binary solutions with $[\mathrm{Ch}] \mathrm{Cl}$. To compare magnitudes, $\Upsilon$ is defined as the ratio of the mole fractions of $[\mathrm{Ch}] \mathrm{Cl}$ in both systems, which is equivalent to the ratio of the $[\mathrm{Ch}] \mathrm{Cl}$ activity coefficients:

$\Upsilon=\frac{x_{[C h] C l, A}}{x_{[C h] C l, B}}=\frac{\gamma_{[C h] C l, B}}{\gamma_{[C h] C l, A}}$

From two experimental binary data sets, interpolated values for the $[\mathrm{Ch}] \mathrm{Cl}$ mole fractions at the same temperature can be found, and $\Upsilon$ calculated, showing similar magnitudes of $[\mathrm{Ch}] \mathrm{Cl}$ activity coefficients, when the ratio is close to one.

\subsection{Consistency of estimated properties}

Beyond the uncertainty of the fusion properties, which can be high due to the nature of the studied substances as well as of the indirect method applied, a very important concept is their reliability, in terms of the error introduced by the use of these properties in the equilibrium calculations. A check of this reliability was performed through the thermodynamic consistency tests proposed by Kang et al. [30] and Cunico et al. [31], which apply pure compound fusion properties to check the quality of the data. These methods are described briefly in the Supplementary Information.

\section{Results and discussion}

\subsection{Solid-liquid phase diagrams}

The phase diagrams measured for the ten selected systems $-[\mathrm{Ch}] \mathrm{Cl}(1)+\mathrm{IC}(2)-$ retained for the assessment of $[\mathrm{Ch}] \mathrm{Cl}$ fusion properties are plotted in Fig. 2 and listed in Table S1 of Supplementary Information.

The data show a similar behavior in all the solubility curves. The 


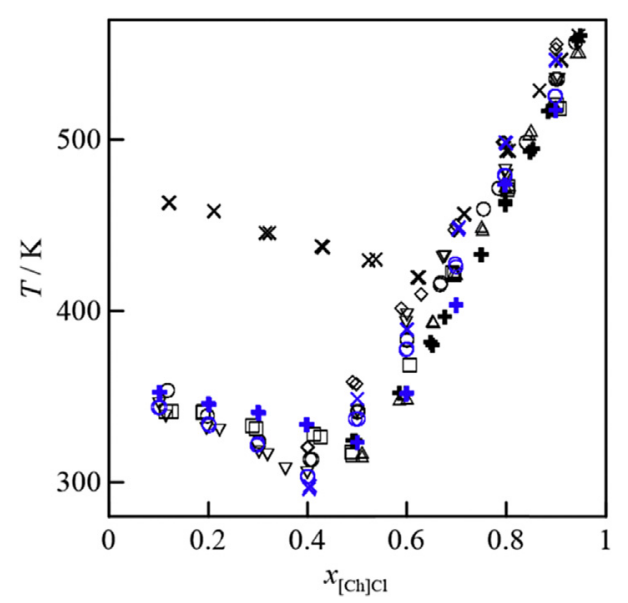

Fig. 2. Solid-liquid phase diagrams for the $\mathrm{ChCl}+$ Ionic compounds systems studied. $[\mathrm{Ch}] \mathrm{Cl}(1)+(\bigcirc)[\mathrm{Ch}][\mathrm{Ac}](2) ;(\boldsymbol{+})[\mathrm{Ch}][\mathrm{Prop}](2) ;(\diamond)[\mathrm{Ch}][\mathrm{Buta}](2) ;(\square)\left[\mathrm{N}_{4444}\right] \mathrm{Cl}(2) ;(\triangle)$ $\left[\mathrm{P}_{4444}\right] \mathrm{Cl}(2) ;(\nabla)[\mathrm{BzCh}] \mathrm{Cl}(2) ;(\mathbf{x})\left[\mathrm{C}_{4} \mathrm{mpyr}\right] \mathrm{Cl}(2) ;(\mathbf{x})[\mathrm{Ch}]\left[\mathrm{NTf}_{2}\right](2) ;(\mathrm{O})\left[\mathrm{C}_{2} \mathrm{mim}\right] \mathrm{Cl}(2) ;$ $(+)\left[\mathrm{C}_{2} \mathrm{OHmim}\right] \mathrm{Cl}(2)$.

solubility curve of [Ch][Prop] was not possible to measure because this compound is liquid at room temperature, preventing the use of the experimental methodology applied in this work. The eutectic points of all the other systems studied depend essentially on the fusion properties of the IC in solution.

\subsection{Evaluation of the ideality of the studied systems}

\subsubsection{Estimation of the activity coefficients by COSMO-RS}

The activity coefficients of $[\mathrm{Ch}] \mathrm{Cl}$ at equimolar composition were estimated by COSMO-RS at three temperatures $(T=300,400$ and $500 \mathrm{~K}$ ) and are reported in Table S2, while the curves at the full composition range can be found in Fig. S2 of supplementary information.

According to the equimolar data, all systems show a quasi-ideal behavior with exception of the mixture containing $\left[\mathrm{N}_{4444}\right] \mathrm{Cl}$. However, the value of the activity coefficients of these systems is still adequate in the concentrated $[\mathrm{Ch}] \mathrm{Cl}$ composition region (see Fig. S2), and thus they were also considered in this work. The system $[\mathrm{Ch}] \mathrm{Cl}+[\mathrm{Ch}][\mathrm{Ac}]$ presents a strong negative deviation to the ideal behavior at low temperatures, which decreases rapidly with increasing temperature. Therefore, a quasi-ideal behavior is expected close to the fusion temperature of $[\mathrm{Ch}] \mathrm{Cl}$ and the data were also considered. For all systems, a fast decrease in the non-ideality of the solution is observed when the temperature is increased (see Figs. S2 and S3). This is related with the weakening effect of the temperature upon the hydrogen bonding that are the dominant interactions on these systems.

The experimental activity coefficients of the ten systems studied were calculated by Eq. (1) and are reported in Table S1 along with the solubility data. These values further confirm the ideality of the studied systems.

\subsection{2. $r$-method}

All the possible combinations for comparing two different binary systems were explored, and for each system, the values of $\Upsilon$ that present maximum deviation from unity are summarized in Table S3. The systems showing the most different behavior between each other are $[\mathrm{Ch}] \mathrm{Cl}+[\mathrm{Ch}][\mathrm{Buta}]$ and $[\mathrm{Ch}] \mathrm{Cl}+\left[\mathrm{C}_{2} \mathrm{OHmim}\right] \mathrm{Cl}$ and $[\mathrm{Ch}] \mathrm{Cl}+[\mathrm{Ch}]\left[\right.$ Buta] and $[\mathrm{Ch}] \mathrm{Cl}+\left[\mathrm{N}_{4444}\right] \mathrm{Cl}$. Four pairs of systems show a value of $\mathrm{Y}=1$ : $[\mathrm{Ch}] \mathrm{Cl}+[\mathrm{Ch}][\mathrm{Prop}]$ and $[\mathrm{Ch}] \mathrm{Cl}+\left[\mathrm{N}_{4444}\right] \mathrm{Cl}$ or $\left[\mathrm{C}_{2} \mathrm{OHmim}\right] \mathrm{Cl},[\mathrm{Ch}] \mathrm{Cl}+\left[\mathrm{N}_{4444}\right] \mathrm{Cl}+\left[\mathrm{C}_{2} \mathrm{OHmim}\right] \mathrm{Cl}$ and $\left[\mathrm{P}_{4444}\right]$

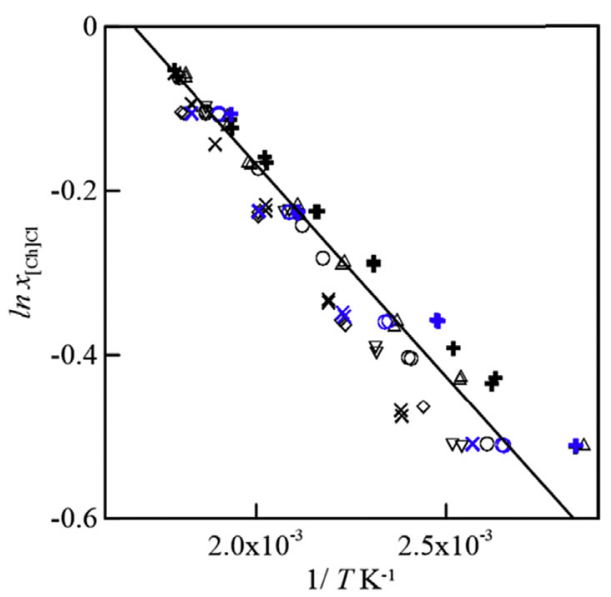

Fig. 3. Plot of the regression by equation (2) of the experimental data for the solubility of $\mathrm{ChCl}$ in $\mathrm{ChCl}+$ Ionic compounds systems. [Ch]Cl(1) $+(\bigcirc)[\mathrm{Ch}][\mathrm{Ac}](2) ;(+)[\mathrm{Ch}]$ [Prop] $(2) ;(\diamond)[\mathrm{Ch}][\mathrm{Buta}](2) ;(\square)\left[\mathrm{N}_{4444}\right] \mathrm{Cl}(2) ;(\triangle)\left[\mathrm{P}_{4444}\right] \mathrm{Cl}(2) ;(\nabla)[\mathrm{BzCh}] \mathrm{Cl}(2) ;(\mathbf{x})$ $\left[\mathrm{C}_{4} \mathrm{mpyr}\right] \mathrm{Cl}(2) ;(\mathbf{x})[\mathrm{Ch}]\left[\mathrm{NTf}_{2}\right](2) ;(\mathrm{O})\left[\mathrm{C}_{2} \mathrm{mim}\right] \mathrm{Cl}(2) ;(+)\left[\mathrm{C}_{2} \mathrm{OHmim}\right] \mathrm{Cl}(2)$. (-) ideal solution $\left(T_{\text {fus },[\mathrm{Ch}] \mathrm{Cl}}=597 \mathrm{~K}, \Delta_{\text {fus }} H_{[\mathrm{Ch}] \mathrm{Cl}}=4300 \mathrm{~J} \cdot \mathrm{mol}^{-1}\right)$.

$\mathrm{Cl}+\left[\mathrm{C}_{2} \mathrm{mim}\right] \mathrm{Cl}$, but all the others are close enough to 1 to consider that they have a very similar behavior, and so to be used in the assessment of the fusion properties.

\subsection{Assessment of the fusion properties of [Ch]Cl}

After the establishment of the quasi-ideality of the ten systems selected, the experimental data were fitted using Eq. (2). To do so, only the experimental information, for each binary system, comprising choline chloride mole fractions higher than 0.6 , was considered. Fig. 3 shows the results of the linear regression.

The calculated fusion properties of choline chloride are $T_{\text {fus, [Ch] }}$ $\mathrm{Cl}=597 \pm 7 \mathrm{~K}$ and $\Delta_{\text {fus }} H_{[\mathrm{Ch}] \mathrm{Cl}}=4300 \pm 600 \mathrm{~J} \mathrm{~mol}^{-1}$. The deviation of these values to those obtained by applying Eq. (2) to each individual system (Table S4) are: $s\left(T_{\text {fus, }[\mathrm{Ch}] \mathrm{Cl}}\right)=11 \mathrm{~K}$ and $\mathrm{s}\left(\Delta_{\mathrm{fus}} H_{[\mathrm{Ch}]}\right.$ $\mathrm{Cl})=593 \mathrm{~J} \mathrm{~mol}^{-1}$, close to the uncertainty of the estimated properties.

The deviations increase for lower concentrations of $[\mathrm{Ch}] \mathrm{Cl}$, where an increase deviation to ideality is observed. However, all curves converge for concentrated choline chloride mixtures, with the experimental data showing small deviations from the fit and allowing a good estimation of the fusion properties. Given that the compound decomposes before melting there are no literature data of the enthalpy of fusion of $[\mathrm{Ch}] \mathrm{Cl}$ to compare with the values here estimated. Abbott et al. [1] proposed a value for the fusion temperature of $[\mathrm{Ch}] \mathrm{Cl}$, that is probably a decomposition temperature. This is somewhat lower than the value estimated in this work $(\Delta T \approx$ $22 \mathrm{~K}$ ), as expected for a decomposition temperature.

\subsection{Validation of the results}

The values of the three quality factors described in Supporting Information [(S3.4), (S3.7) and (S3.10)] are presented in Table S5. The NRTL model [32] was used to fit the solid-liquid equilibria diagrams (parameters given in Table S6). All systems show very satisfactory quality factors by the three consistency tests. The system which shows a lower quality is $[\mathrm{Ch}] \mathrm{Cl}+\left[\mathrm{P}_{4444}\right] \mathrm{Cl}$.

An additional verification of the results was performed through the reproduction of the solid-liquid phase equilibria of all systems by COSMO-RS model. For that, the properties estimated for $[\mathrm{Ch}] \mathrm{Cl}$ and the other components shown in Table 1 (experimental and estimated) were used. Fig. 4 presents all the resulting diagrams 

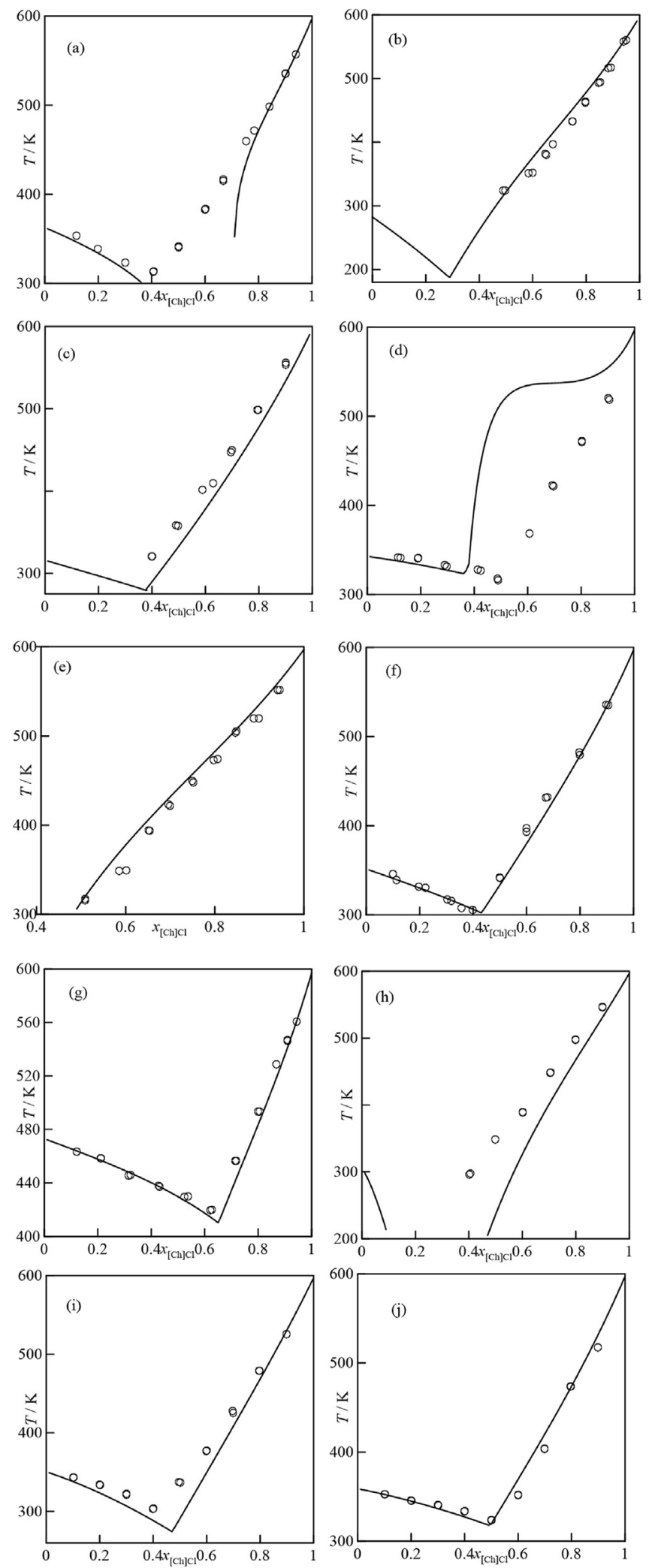

Fig. 4. Solid-liquid phase diagrams estimated by COSMO-RS for $[\mathrm{Ch}] \mathrm{Cl}(1)+(2)$, being (2): (a) [Ch][Ac]; (b) [Ch][Prop]; (c) [Ch][Buta]; (d) [N $\left.\mathrm{N}_{4444}\right] \mathrm{Cl}$; (e)[P $\left.\mathrm{P}_{4444}\right] \mathrm{Cl}$; (f) [BzCh]Cl; (g) $\left[\mathrm{C}_{4}\right.$ mpyr $] \mathrm{Cl} ;(\mathrm{h})[\mathrm{Ch}]\left[\mathrm{NTf}_{2}\right] ; \quad(\mathrm{i})\left[\mathrm{C}_{2} \mathrm{mim}\right] \mathrm{Cl} ;(\mathrm{j})\left[\mathrm{C}_{2} \mathrm{OHmim}\right] \mathrm{Cl} .(-)$ COSMO-RS (O) Experimental data. obtained, showing a very satisfactory representation of the experimental data, with three exceptions: the solubility curves of the systems $[\mathrm{Ch}] \mathrm{Cl}+[\mathrm{Ch}][\mathrm{Ac}]$ and $[\mathrm{Ch}]\left[\mathrm{NTf}_{2}\right]$ do not intersect because of the low value of the activity coefficients at low temperatures, and the system $[\mathrm{Ch}] \mathrm{Cl}+\left[\mathrm{N}_{4444}\right] \mathrm{Cl}$ presents a curious concavity resulting from a large deviation of the ideality estimated by COSMO-RS, which is in total disagreement with the quasi-ideal behaviour found from the experimental solid-liquid equilibrium data.

The eutectic points obtained from the experimental data, and the different models used (NRTL and COSMO-RS) are presented in Table S7, showing relevant differences as COSMO-RS is a pure predictive model. These results also show the importance to find the eutectic coordinates experimentally.

Finally, it is important to reinforce that the methodology here proposed can potentially be expanded to other ionic compounds that decompose upon melting, giving tools for a much better analysis, thermodynamic representation and eventually screening of new DES.

\section{Conclusions}

To obtain an estimate of the fusion properties of choline chloride, experimental solid-liquid phase diagrams of ten quasi-ideal liquid eutectic mixtures composed by choline chloride and different ionic compounds were measured. Their ideality was evaluated through the activity coefficients calculated by COSMO-RS as well as by comparing the activity coefficients ratio of choline chloride in each pair of binary solutions. The estimated fusion temperature and enthalpy of pure choline chloride was found to be: $T_{f u s,[\mathrm{Ch}] \mathrm{Cl}}=597 \pm 7 \mathrm{~K}$ and $\Delta_{f u s} \mathrm{H}_{[\mathrm{Ch}] \mathrm{Cl}}=4300 \pm 600 \mathrm{~J} \mathrm{~mol}^{-1}$. The robustness of the method here applied was additionally verified using thermodynamic consistency tests and by the prediction of the solid-liquid curves with COSMO-RS model.

\section{Acknowledgements}

This work was developed in the scope of the project CICECOAveiro Institute of Materials, POCI-01-0145-FEDER-007679 (Ref. FCT UID/CTM/50011/2013) and Project POCI-01-0145-FEDER006984 - Associate Laboratory LSRE-LCM, both funded by FEDER through COMPETE2020 - Programa Operacional Competitividade e Internacionalização (POCI) - and by national funds through FCT Fundação para a Ciência e a Tecnologia. M.A.R.M acknowledges FCT for her PhD grant (SFRH/BD/87084/2012). J.O. and L.F. thank the financing provided by the Spanish Government, Ministerio de Economia y Competitividad (MINECO), under the project CTQ201237114 and the short-stay grant EEBB-I-16-11792.

\section{Appendix A. Supplementary data}

Electronic Supplementary Information (ESI) available: Synthesis methodology, thermogravimetric analysis, consistency tests theory, solid-liquid equilibria experimental data, equimolar activity coefficients estimated by COSMO-RS, results of $\Upsilon$-method, results of the consistency tests, NRTL modelling, representation of the activity coefficient estimated by COSMO-RS and solid-liquid phase diagram predicted by COSMO-RS.

Supplementary data related to this article can be found at http:// dx.doi.org/10.1016/j.fluid.2017.03.015.

\section{References}

[1] A.P. Abbott, G. Capper, D.L. Davies, R.K. Rasheed, V. Tambyrajah, Novel solvent properties of choline chloride/urea mixtures, Chem. Commun. 99 (2003) 70-71, http://dx.doi.org/10.1039/b210714g. 
[2] Q. Zhang, K. De Oliveira Vigier, S. Royer, F. Jérôme, Deep eutectic solvents: syntheses, properties and applications, Chem. Soc. Rev. 41 (2012) 7108-7146, http://dx.doi.org/10.1039/c2cs35178a.

[3] B. Tang, K.H. Row, Recent developments in deep eutectic solvents in chemical sciences, Monatsh. Für Chem. - Chem. Mon. 144 (2013) 1427-1454, http:/| dx.doi.org/10.1007/s00706-013-1050-3.

[4] D. Carriazo, M.C. Serrano, M.C. Gutiérrez, M.L. Ferrer, F. del Monte, Deepeutectic solvents playing multiple roles in the synthesis of polymers and related materials, Chem. Soc. Rev. 41 (2012) 4996-5014, http://dx.doi.org/ 10.1039/c2cs15353j.

[5] A. Hayyan, F.S. Mjalli, I.M. Alnashef, Y.M. Al-Wahaibi, T. Al-Wahaibi, M.A. Hashim, Glucose-based deep eutectic solvents: physical properties, J. Mol. Liq. 178 (2013) 137-141, http://dx.doi.org/10.1016/ j.molliq.2012.11.025.

[6] M. Francisco, A. van den Bruinhorst, M.C. Kroon, Low-transition-temperature mixtures (LTTMs): a new generation of designer solvents, Angew. Chem. Int. Ed. 52 (2013) 3074-3085, http://dx.doi.org/10.1002/anie.201207548.

[7] E.L. Smith, A.P. Abbott, K.S. Ryder, Deep eutectic solvents (DESs) and their applications, Chem. Rev. 114 (2014) 11060-11082, http://dx.doi.org/10.1021/ cr300162p.

[8] K. Radošević, M. Cvjetko Bubalo, V. Gaurina Srček, D. Grgas, T. Landeka Dragičević, I. Radojčić Redovniković, Evaluation of toxicity and biodegradability of choline chloride based deep eutectic solvents, Ecotoxicol. Environ. Saf. 112 (2015) 46-53, http://dx.doi.org/10.1016/j.ecoenv.2014.09.034.

[9] A.P. Abbott, D. Boothby, G. Capper, D.L. Davies, R.K. Rasheed, Deep eutectic solvents formed between choline chloride and carboxylic acids: versatile alternatives to ionic liquids, J. Am. Chem. Soc. 126 (2004) 9142-9147, http:// dx.doi.org/10.1021/ja048266j.

[10] Z. Maugeri, P. Domínguez de María, Novel choline-chloride-based deepeutectic-solvents with renewable hydrogen bond donors: levulinic acid and sugar-based polyols, RSC Adv. 2 (2012) 421-425, http://dx.doi.org/10.1039/ C1RA00630D.

[11] A. Paiva, R. Craveiro, I. Aroso, M. Martins, R.L. Reis, A.R.C. Duarte, Natural deep eutectic solvents - solvents for the 21st century, ACS Sustain. Chem. Eng. 2 (2014) 1063-1071, http://dx.doi.org/10.1021/sc500096j.

[12] F. Chemat, H. Anjum, A.M. Shariff, P. Kumar, T. Murugesan, Thermal and physical properties of (Choline chloride+urea+l-arginine) deep eutectic solvents, J. Mol. Liq. 218 (2016) 301-308, http://dx.doi.org/10.1016/ j.molliq.2016.02.062.

[13] G.J. Maximo, R.J.B.N. Santos, P. Brandao, J.M.S.S. Esperanca, M.C. Costa, A.J.A. Meirelles, M.G. Freire, J.A.P. Coutinho, Generating ionic liquids from ionic solids: an investigation of the melting behavior of binary mixtures of ionic liquids, Cryst. Growth Des. 14 (2014) 4270-4277, http://dx.doi.org/ $10.1021 / \mathrm{cg} 500655 \mathrm{~s}$.

[14] O. Stolarska, A. Soto, H. Rodríguez, M. Smiglak, Properties modification by eutectic formation in mixtures of ionic liquids, RSC Adv. 5 (2015) 22178-22187, http://dx.doi.org/10.1039/C4RA17268J.

[15] O. Stolarska, H. Rodríguez, M. Smiglak, Eutectic mixtures of pyrrolidiniumbased ionic liquids, Fluid Phase Equilib. 408 (2016) 1-9, http://dx.doi.org/ 10.1016/j.fluid.2015.08.007.

[16] A. Klamt, COSMO-RS From Quantum Chemistry to Fluid Phase
Thermodynamics and Drug Design, Elsevier, Amsterdam, The Netherlands, 2005.

[17] Y. Fukaya, Y. Iizuka, K. Sekikawa, H. Ohno, Bio ionic liquids: room temperature ionic liquids composed wholly of biomaterials, Green Chem. 9 (2007) 1155-1157, http://dx.doi.org/10.1039/b706571j.

[18] N. Muhammad, M.I. Hossain, Z. Man, M. El-Harbawi, M.A. Bustam, Y.A. Noaman, N.B. Mohamed Alitheen, M.K. Ng, G. Hefter, C.-Y. Yin, Synthesis and physical properties of choline carboxylate ionic liquids, J. Chem. Eng. Data 57 (2012) 2191-2196, http://dx.doi.org/10.1021/je300086w.

[19] M. Petkovic, J.L. Ferguson, H.Q.N. Gunaratne, R. Ferreira, M.C. Leitão K.R. Seddon, L.P.N. Rebelo, C.S. Pereira, Novel biocompatible cholinium-based ionic liquids - toxicity and biodegradability, Green Chem. 12 (2010) 643-649, http://dx.doi.org/10.1039/b922247b.

[20] G.J. Janz, R.P.T. Tomkins, Nonaqueous Electrolytes Handbook, Academic Press, New York-London, 1972.

[21] J. Jenck, Palladium Catalyzed Carbonylation of Conjugated Dienes with Catalyst Recycle, 1984. US 4454333 A.

[22] C.H.S. Hiroshi Ogawa, Tatsuhiro Suwa, Adhesive Composition and Optical Member, 2009. US 20090014123 A1.

[23] P. Nockemann, K. Binnemans, B. Thijs, T.N. Parac-Vogt, K. Merz, A.-V. Mudring P.C. Menon, R.N. Rajesh, G. Cordoyiannis, J. Thoen, J. Leys, C. Glorieux, Temperature-driven mixing-demixing behavior of binary mixtures of the ionic liquid choline bis(trifluoromethylsulfonyl)imide and water, J. Phys. Chem. B 113 (2009) 1429-1437, http://dx.doi.org/10.1021/jp808993t.

[24] I. Skarmoutsos, D. Dellis, R.P. Matthews, T. Welton, P.A. Hunt, Hydrogen bonding in 1-butyl- and 1-Ethyl-3-methylimidazolium chloride ionic liquids, J. Phys. Chem. B 116 (2012) 4921-4933, http://dx.doi.org/10.1021/jp209485y.

[25] S.J. Zhang, X.M. Lu, Q. Zhou, X. Li, X. Zhang, S. Lu, Ionic Liquids: Physicochemical Properties, first ed., Elsevier, Oxford - United Kingdom, 2009.

[26] J.M. Prausnitz, R.N. Lichtenthaler, E.G. Azevedo, Molecular Thermodynamics Fluid Phase Equilibria, Prentice-Hall, 1986.

[27] J. Gmehling, B. Kolbe, M. Kleiber, J. Rarey, Chemical Thermodynamics for Process Simulation, Wiley-VCH, 2012.

[28] J.A.P. Coutinho, S.I. Andersen, E.H. Stenby, Evaluation of activity coefficient models in prediction of alkane solid-liquid equilibria, Fluid Phase Equilib. 103 (1995) 23-39, http://dx.doi.org/10.1016/0378-3812(94)02600-6.

[29] E. Ruiz, V.R. Ferro, J. Palomar, J. Ortega, J.J. Rodriguez, Interactions of ionic liquids and acetone: thermodynamic properties, quantum-chemical calculations, and NMR analysis, J. Phys. Chem. B 117 (2013) 7388-7398, http:// dx.doi.org/10.1021/jp402331y.

[30] J.W. Kang, V. Diky, R.D. Chirico, J.W. Magee, C.D. Muzny, A.F. Kazakov, K. Kroenlein, M. Frenkel, Algorithmic framework for quality assessment of phase equilibrium data, J. Chem. Eng. Data 59 (2014) 2283-2293, http:// dx.doi.org/10.1021/je500327k.

[31] L.P. Cunico, R. Ceriani, B. Sarup, J.P. O'Connell, R. Gani, Data, analysis and modeling of physical properties for process design of systems involving lipids, Fluid Phase Equilib. 362 (2014) 318-327, http://dx.doi.org/10.1016 j.fluid.2013.10.040.

[32] H. Renon, J.M. Prausnitz, Local compositions in thermodynamic excess functions for liquid mixtures, AIChE J. 14 (1968) 135-144, http://dx.doi.org/ 10.1002/aic.690140124. 